\title{
Medfødte misdannelser og fars yrkeseksposisjon
}

\section{Hypoteser basert på funn fra tidligere studier etterprøvet i et norsk registermateriale}

\author{
Ågot Irgens ${ }^{1}$, Kirsti Krüger ${ }^{1}$, Anne Helene Skorve ${ }^{1}$, Lorentz M. Irgens ${ }^{2}$ \\ 1. Yrkesmedisinsk avdeling, Haukeland Sykehus, 5021 Bergen \\ 2. Medisinsk fødselsregister, Universitetet i Bergen
}

\begin{abstract}
SAMMENDRAG
Hypoteser basert på funn fra tidligere studier av misdannelser hos barn av fedre i ulike yrkesgrupper (1), ble etterprøvet i et norsk registermateriale. Materialet besto av data fra Medisinsk fødselsregister (MFR) 1970-93, koblet med data fra Folke- og boligtellinger (FOB) fra 1970, 1980 og 1990 med opplysninger om bl.a. fars yrke. Som referansepopulasjon ble benyttet barn av fedre med alle andre yrker enn det som ble analysert. Barn av malere hadde tendens til økt risiko for spina bifida - OR 2,03 (CI 0,99-3,75) og barn av trykkeriarbeidere hadde økt risiko for klumpfot - OR 1,52 (CI 1,10-2,10). Studien har bidradd til å sannsynliggjøre en kausal sammenheng knyttet til påviste samvariasjoner, dog uten å belyse mekanismer. Tidligere positive funn hos barn av fedre i enkelte store yrkesgrupper som lærere, elektriske yrker, salgsrelaterte yrker, bønder og sjåfører ble ikke bekreftet i vårt materiale. Eventuelt falske negative funn kan skyldes lav statistisk styrke på grunn av små grupper eller problemer med ikke differensiell feilklassifisering av eksposisjon.
\end{abstract}

\section{Irgens Å, Krüger K, Skorve AH, Irgens LM. Birth defects and paternal occupational exposure. Hypotheses derived from previous studies tested in a Norwegian registry material. Nor J Epidemiol 1997; 7 (1): 13-18.}

\section{ENGLISH SUMMARY}

\begin{abstract}
Aim. To test, on the basis of a Norwegian registry material, previously established hypotheses on associations of birth defects with paternal occupation (1).

Method. The study was based on all births in Norway 1970-1993 for which linkage with population censuses 1970, 1980 and 1990 could be obtained - about 1 million births. The reference population was offspring of the group that did not belong to the actual occupation.

Results. Offspring of painters had a tendency of increased risk of spina bifida - OR 2,03 (CI 0,99-3,75) and offspring of printers had an increased risk for talipes - OR 1,52 (CI 1,10-2,10). Positive associations observed previously in offspring of fathers in large occupational groups such as teachers, drivers, electricity related occupations, sales related occupations and agricultural workers were not confirmed in this dataset.

Conclusion. The study gave evidence of cause effect relationships in the confirmed positive associations, though without any clarification of possible mechanisms involved. Possible false negative findings might be due to low statistical power as a result of small occupational groups or non differential problems of misclassification of exposure.
\end{abstract}

\section{INNLEDNING}

Eksponering av far før barnet er konsipert kan være årsak til medfødte misdannelser. Slik eksponering kan føre til endringer i spermienes arvestoff. Tallrike studier har belyst forekomsten av misdannelser hos barn av fedre i ulike yrkesgrupper (2-5). Resultater fra en rekke slike studier er samlet $\mathrm{i}$ boken Male-Mediated Developmental Toxicity (1) (Tabell over disse kan fåes ved henvendelse til forfatteren). Studiene har variert $\mathrm{i}$ design, men i hovedsak har pasientkontrollstudier vært benyttet. Pasienter er oftest hentet fra misdannelsesregistre og kontroller er enten barn med mindre misdannelser eller friske barn født samtidig i samme område. Utvalgsstørrelse, valg av risikomål og justering for mulige effektforvekslere har vært forskjellig. Klassifisering av yrkesgrupper har ikke vært standardisert. Studiene har ledet til en rekke hypoteser som det har vært vanskelig å etterprøve av mangel på tilstrekkelig stort materiale. Data fra Medisinsk fødselsregister koblet med yrkesopplysninger for far fra Folke- og boligtellingene, Statistisk Sentralbyrå, ble benyttet for å etterprøve tidligere påviste sammenhenger. 


\section{MATERIALE OG METODE}

All informasjon om mor og barn ble hentet fra Medisinsk fødselsregister, 1970-93. Til Medisinsk fødselsregister skal meldes alle fødte med svangerskapsvarighet 16 uker eller mer. Alle misdannelser som er diagnostisert inntil en uke etter fødselen skal rapporteres. Alvorlige og synlige misdannelser har best meldedekning. Misdannelser som oppdages etter at barnet forlater fødestedet, er ikke inkludert i registeret. Misdannelsene er kodet ved bruk av modifiserte ICD8 koder $(6$, tabell 1). For hvert barn kan inntil tre misdannelser registreres. Alle fødte, uavhengig av gestasjonsalder, er tatt med i studien.

Opplysninger om fars yrke er hentet fra Folke- og boligtellingene, Statistisk Sentralbyrå. Kobling med folketellingsinformasjon er gjort for 1,2 mill. fødte. Fedrenes yrker ble bestemt ut fra folktellingsinformasjon fra årene 1970, 1980 eller 1990 på grunnlag av yrkestittel og utdannelse. Yrker er kodet ved bruk av 'Nordisk yrkesklassifisering' standard fra 1965 med tre siffer. Siden yrkesopplysninger mellom to folketellinger manglet, valgte vi å benytte informasjon fra folketellingen forut for fødselen. Som referansepopulasjon ble benyttet barn av fedre med alle andre yrker enn det som ble analysert. Opplysninger om far mangler i $10,1 \%$ av materialet. Barn av disse fedrene er inkludert i referansematerialet.

$\mathrm{Vi}$ valgte å ta utgangspunkt i studiene som er referert til i Male-Mediated Developmental Toxicity (1). Enkelte yrker med tidligere positive funn er ikke analysert $\mathrm{i}$ vårt materiale da klassifisering av yrket ut fra nordiske yrkeskoder var vanskelig, eller fordi yrkesgruppene var for små. 36 yrkesgrupper ble analysert og antall barn av fedre i disse yrkene er anført (tabell 2). Generelt er presentert analyseresultatene for alle yrkesgrupper med flere enn 8000 barn og mindre yrkesgrupper med tendens til positive funn.

I alle analyser er brukt eksakte statistiske metoder for beregning av odds ratio med konfidensgrenser fra $2 \times 2$ tabeller (7).

\section{RESUlTATER}

Malere. Tidligere er rapportert økt forekomst av nevralrørsdefekter, ganespalte, klumpfot, polydactyli, syndactyli og reduksjondeformiteter. Vårt materiale viste tendens til økt forekomst av spina bifida og klumpfot (tabell 3). Forøvrig ble det ikke påvist noen samvariasjoner.

Tabell 1. Misdannelser analysert i studien og prevalens for disse i totalpopulasjonen i Norge 1970-93.

\begin{tabular}{|c|c|c|c|}
\hline Misdannelse & Beskrivelse & $\begin{array}{l}\text { prevalens per } 10000 \\
\text { fødte } \mathrm{i} \text { totalmaterialet }\end{array}$ & Misdannelseskode \\
\hline ABS & Anencephalus eller spina bifida & 8,77 & $7409,7410,7419$ \\
\hline Anencephali & $\begin{array}{l}\text { Total eller partiell manglende hjerne og } \\
\text { tilhørende del av hodeskallen }\end{array}$ & 3,70 & 7409 \\
\hline CNS & $\begin{array}{l}\text { Anencephalus eller spina bifida eller andre } \\
\text { misdannelser i nervesystemet }\end{array}$ & 10,10 & $7410,7419,7430-9$ \\
\hline Down syndrom & & 10,33 & 7593 \\
\hline Hareskår & & 5,26 & 7491 \\
\hline Hofteleddsluksasjon & & 31,99 & 7556 \\
\hline Hypospadi & Munning av urinrøret på undersiden av penis & 12,80 & 7522 \\
\hline Isolert ganespalte & & 5,10 & 7490 \\
\hline Klumpfot & & 65,93 & $7541-6,7548-9$ \\
\hline Leppe gane spalte & & 19,10 & $7490-2$ \\
\hline $\begin{array}{l}\text { Leppespalte med eller uten } \\
\text { ganespalte hos gutter }\end{array}$ & & 18,27 & 7491,7492 \\
\hline Oesophagus atresi & $\begin{array}{l}\text { Atresi og stenose av øsofagus, samt tracheo- } \\
\text { øsofagalfistel }\end{array}$ & 1,96 & 7502 \\
\hline Polydakti & & 6,66 & 7550 \\
\hline Pylorusstenose & & 0,13 & 7501 \\
\hline Rectalatresi & & 1,94 & 7512 \\
\hline Reduksjonsdeformiteter & & 5,07 & $7552-5$ \\
\hline Retentio testis & & 14,85 & 7521 \\
\hline Spina bifida & $\begin{array}{l}\text { Manglende dekning av ryggmargen på } \\
\text { grunn av manglende lukning av ryggraden }\end{array}$ & 5,33 & 7410,7419 \\
\hline Syndactyli & & 6,08 & 7551 \\
\hline Uretraatresi & Atresi og stenose av uretra og blærehals & 0,09 & 7536 \\
\hline
\end{tabular}


Tabell 2. Antall barn av fedre i yrkesgrupper med positive funn fra tidligere studier, født i Norge 1970-93 og analysert i denne studien.

\begin{tabular}{|c|c|c|}
\hline Yrkesgruppe & Yrkeskode & Antall barn \\
\hline maler & $781-9$ & 8383 \\
\hline trykkeriarbeider & 803 & 4114 \\
\hline jern, sliper-høvler etc. & 751 & 16638 \\
\hline $\begin{array}{l}\text { aluminiumsindustri- } \\
\text { arbeider }\end{array}$ & $\begin{array}{l}731-2,737,739 \text { og bosatt } \\
\text { nær aluminiumsverk }\end{array}$ & 2837 \\
\hline sveiser & 756 & 13252 \\
\hline smelteverksarbeider & 731 & 4983 \\
\hline metallarbeider & $754,755,757$ & 26023 \\
\hline skogsarbeider & 402,441 & 4537 \\
\hline papirarbeider & 836 & 836 \\
\hline finer/treplatearbeider & 773 & 821 \\
\hline snekker & $775-7$ & 10901 \\
\hline sagbruksarbeider & 772 & 3649 \\
\hline bilmekaniker & 876 & 1967 \\
\hline sjåfør & $640-9$ & 55621 \\
\hline jernbarnearbeider & $652-4$ & 2205 \\
\hline salgsrelatert & $300-99$ & 55974 \\
\hline oljearbeider & $530-1$ & 1786 \\
\hline gummivarearbeider & 852 & 1288 \\
\hline gruvearbeider & 501 & 3595 \\
\hline tekstilarbeider & $701-19$ & 3143 \\
\hline spinner & 702 & 241 \\
\hline vever & 703 & 363 \\
\hline bryggeriarbeider & 824 & 997 \\
\hline servitør & $921-2$ & 2978 \\
\hline kokk & $912-3$ & 6839 \\
\hline lærer & 064 & 22949 \\
\hline vaktmester & 931 & 3326 \\
\hline elektrisk yrke & $761-9$ & 41396 \\
\hline bonde & $401,403-5,411-3$ & 48763 \\
\hline farmasøyt & $050-1$ & 221 \\
\hline lege & 031 & 5876 \\
\hline geolog & 014 & 432 \\
\hline arkitekt & 001 & 1674 \\
\hline arkitektutdannet & & 1129 \\
\hline fisker & $430-9$ & 16507 \\
\hline politi & 903 & 5794 \\
\hline militært ansatt & A-A30 & 56786 \\
\hline
\end{tabular}

Trykkeriarbeidere. Tidligere er rapportert økt forekomst av anencephalus, klumpfot, uretra atresi, ganespalte, rectal atresi og polydactyli. Vårt materiale viste økt forekomst av klumpfot (tabell 3), forøvrig ble ingen sammenhenger påvist.

Metallindustri. Tidligere er rapportert økt risiko for nevralrørsdefekter, økt forekomst av ganespalte hos støperi-, og smelteverksarbeidere, økt forekomst av Down syndrom og syndactyli hos barn av metallarbeidere og økt forekomst av spina bifida hos barn av sveisere og metallarbeidere. Våre funn viste en tendens til økt risiko for syndactyli hos barn av metallarbeidere. Forøvrig ble det ikke påvist noen samvariasjoner (tabell 3).

Skogsarbeidere. Tidligere rapportert er økt risiko for anencephalus, spina bifida, leppespalte, syndactyli og pylorusstenose hos barn av skogsarbeidere. I vårt materiale var prevalensen av syndactyli nesten doblet (tabell 3).
Transportrelaterte yrker. Tidligere er rapportert økt forekomst av ganespalte, leppespalte, klumpfot, syndactali, leppeganespalte og anencephalus og/eller spina bifida hos barn av mannlige sjåfører og økt forekomst av leppe- og/eller ganespalte, uretra atresi og nevralrørsdefekter hos barn av jernbanearbeidere. Ingen funn i vårt materiale (tabell 3 ).

Salgsrelaterte yrker. Tidligere funn er økt forekomst av leppe- og/eller ganespalte, polydactyli, klumpfot, anencephalus og/eller spina bifida, hypospadi, Down syndrom, rektal og uretra atresi. Ingen funn i vårt materiale (tabell 3).

Laerere. Tidligere funn er økt forekomst av Down syndrom og urinveisobstruksjon hos barn av lærere. Vår materiale viste ingen økt risiko for de analyserte misdannelsene (tabell 3).

Elektriske yrker. Tidligere funn er økt forekomst av nevralrørsdefekter, spina bifida, leppeganespalte og syndactyli. Vårt materiale støttet ikke tidligere funn (tabell 3).

Bønder. Tidligere funn er økt forekomst av nevralrørsdefekter, anencephalus, Down syndrom og reduksjonsdefekter hos barn av mannlige landbruksarbeidere, økt forekomst av hypospadi hos barn av bønder og gartnere. Våre materiale støttet ikke tidligere funn (tabell 3).

Andre yrker. Tidligere funn er økt risiko for syndactyli hos barn av arkitekter og økt forekomst av polydactyli hos barn av fedre i forsvaret. Vårt materiale påviste økt forekomst av syndactyli hos barn av arkitekter (som også inkluderer bygningssjefer, generalplanleggere og reguleringssjefer), klassifisering på grunnlag av arkitektutdannelse og yrkesbetegnelse arkitekt ga få tilfeller (tabell 3).

\section{DISKUSJON}

Vårt materiale ga en rekke negative funn. Foruten problemer med for små grupper, kan dette skyldes feilklassifisering. Klassifisering på grunnlag av yrkeskode vil resultere i grupper med svært heterogen eksposisjon mht. potensielle risikofaktorer. Fars eksposisjon og eksponeringsgrad kan være avhengig av land, type arbeidsplass, spesialisering i yrket, utdannelse og barnets fødselsår, og kan derfor variere sterkt blant arbeidstakere med samme yrkestittel.

Feilklassifisering av yrke er et spesielt problem i vårt datamateriale. Siden yrkesopplysninger ikke er oppgitt i forbindelse med den aktuelle graviditet, men i folketellingen forut for denne, vil endret yrke siden siste folketelling føre til feilklassifisering. Grad av slik feilklassifisering vil være avhengig av stabiliteten i yrket.

Feilklassifisering av yrket vil også kunne oppstå siden koding av yrket er så grov at flere yrkesgrupper kodes likt. Den eksponerte gruppen kan også være feilaktig redusert ved at arbeidstakere som f.eks. platearbeidere kan være klassifisert med annen yrkeskode som f.eks. produksjonsarbeider eller hjelpearbeider. 
Tabell 3. Forekomst av ulike misdannelser hos barn av fedre i endel yrker og i referansepopulasjonene i Norge 19701993 samt odds ratio med $95 \%$ konfidensintervall.

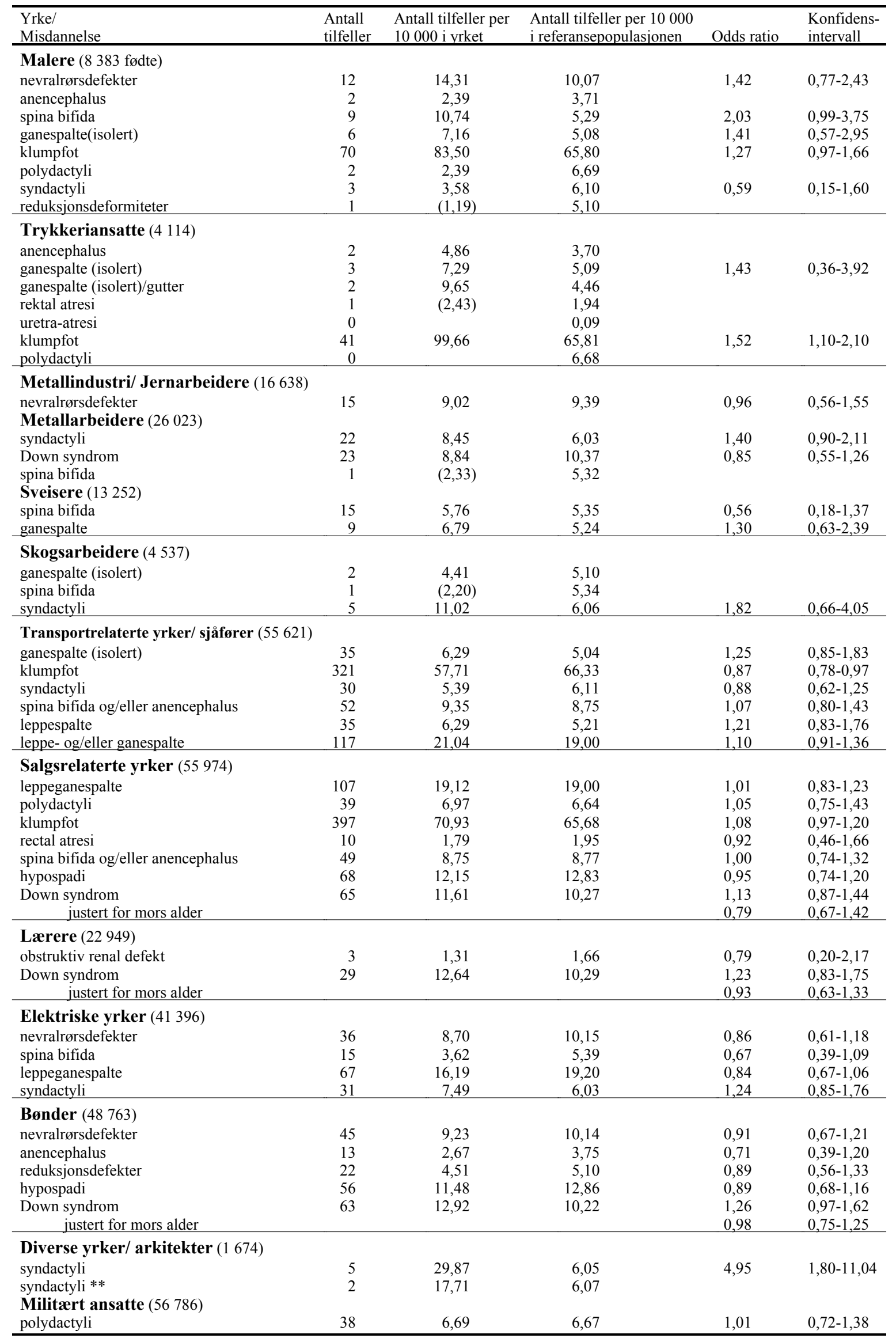

** Barn av arkitektutdannete 
Feilklassifiseringproblemer antas også å forekomme i varierende grad $\mathrm{i}$ de tidligere studiene. I tillegg kan vårt valg av yrker som skal sammenlignes med yrkesgrupper i de tidligere studiene, være feilaktig på grunn av ulike kodesystemer og yrkesangivelser. All feilklassifisering vil være ikkedifferensiell og føre til en konservativ skjevhet av risikoestimatene.

For svangerskapsutfallene lav fødselsvekt og kort svangerskapsvarighet, knyttet til mors yrke, har vi sett på prevalenser ved klassifisering av hele datamaterialet i forhold til et delmateriale bestående av treårsperioden etter hver folketelling. En tendens til økt risiko i totalmaterialet ble oftest gjenfunnet i delmaterialet, men med høyere risiko (8), noe som underbygger antakelsen om feilklassifisering.

Siden Medisinsk fødselsregister bare inneholder misdannelser som er diagnostisert inntil en uke etter fødselen, forekommer underrapportering av misdannelser. Alvorlige og synlige misdannelser har best meldedekning. Siden inntil tre misdannelser kan meldes, kan det føre til at enkelte av multiple misdannelser utelates. Dette kan føre til at vårt materiale har lavere forekomst av enkelte misdannelser enn andre materialer, men fører ellers neppe til differensiell feilklassifisering.

Barn med manglende fars opplysning er inkludert $i$ referansepopulasjonen. Dette kan i enkelte tilfeller føre til en feilklassifisering av eksponering. Forekomst av de rapporterte misdannelsene for barn med og uten fars opplysning er stort sett overensstemmende, bortsett fra økt forekomst av anencephalus og spina bifida hos barn uten farsopplysning. Feilklassifiseringen vil følgelig kunne føre til konservative risikoestimat for disse misdannelsene.

Hensikten med gjennomføringen av de tidligere studiene har variert. Noen studier har fremsatt en hypotese om økt risiko for en misdannelse hos barn av fedre med en konkret yrkeseksposisjon. For flere av studiene har hensikten vært å foreta en screening av alle yrker og alle misdannelser og på den måten kartlegge yrkesgrupper hvor avkommet har økt misdannelsesrisiko. Ved den sistnevnte fremgangsmåten er sjansen for et tilfeldig funn betydelig og avhengig av antall analyserte sammenhenger. I tillegg byr det på problemer å tolke resultatene mekanistisk. Fars eksponering kan være svært heterogen, og effekten av denne er bare en av de faktorer som kan påvirke fosterutviklingen. Forekomst av relevante eksponeringer bør derfor være høy innen en yrkesgruppe for å kunne observere økt forekomst av spesifikke misdannelser hos barna.

Svært få av de tidligere rapporterte funn ble bekreftet med signifikante funn ved vår analyse. Dette kan skyldes lav statistisk styrke i flere analyser på grunn av konservative risikoestimat, små eksponerte grupper og sjeldne tilstander. Til tross for at vårt totalmateriale er stort (ca. 1,2 mill. fødte), har det, for små yrkesgrupper, ikke tilstrekkelig størrelse til at økt risiko for misdannelser kan avdekkes. Tendens til økt risiko for misdannelser er derfor også angitt under positive funn som kan tillegges en viss vekt:

Malere. Studier har tilskrevet uønsket svangerskapsutfall hos barn av malere til eksponering for bl.a. løsemidler, metaller og epoxy. Sammenheng med CNS defekter har vært rapportert i fem uavhengige studier med overrisikoestimat fra 2,5 til 4,9 (9-13). I to studier $(11,14)$ er det funnet økt forekomst av ganespalte, en studie har funnet økt risiko for klumpfot, polydactyli, syndactyli og reduksjondeformiteter (12). En tendens til økt forekomst av spina bifida og klumpfot ble gjenfunnet $\mathrm{i}$ vårt materiale.

Trykkeriarbeidere. Økt forekomst har vært rapportert av anencephalus (9), klumpfot, uretra atresi (11), ganespalte (14), rectal atresi og polydactyli (13). Våre funn viser økt risiko for klumpfot, men ingen sammenheng for ganespalte. Tidligere er påvist økt risiko for leppespalte (med eller uten ganespalte) hos trykkeriarbeideres guttebarn i Norge 1967-1986 (5). For denne gruppen ble en ikke-signifikant økt forekomst (OR 1,59) gjenfunnet i vår kohort, men basert på kun seks tilfeller.

Metallindustri. Økt forekomst av ganespalte hos støperi- og smelteverksarbeidere, økt forekomst av Down syndrom og syndactyli hos metallarbeidere (11), samt økt forekomst av spina bifida hos sveisere og metallarbeidere (13) har vært rapportert. Vårt materiale viser en ikkesignifikant økt risiko for syndactyli hos barn av metallarbeidere.

Skogsarbeidere. Økt risiko har vært rapportert for anencephalus, spina bifida, leppespalte, syndactyli og pylorusstenose hos barn av skogsarbeidere (11). En tendens til økt forekomst av syndactyli ble sett $\mathrm{i}$ vårt materiale, men er basert på få tilfeller.

Transportrelaterte yrker. To studier rapporterte økt risiko for flere misdannelser, deriblant nevralrørsdefekter $(13,16)$. Tre studier har sett på barn av mannlige sjåfører. Disse har funnet økt risiko for misdannelsene ganespalte, leppespalte, klumpfot, syndactali, leppeganespalte og anencephalus og/eller spina bifida $(11,13,17)$. Ingen av disse funnene ble bekreftet $i$ vår studie.

Salgsrelaterte yrker. Økt forekomst av misdannelsene leppe- og/eller ganespalte, polydactyli, klumpfot, anencephalus og/eller spina bifida, hypospadi, Down syndrom, rektal og uretra atresi er rapportert hos barnet dersom faren arbeidet i salgsrelaterte yrker $(11,13,17)$. Biologiske mekanismer har ikke vært diskutert. Til tross for store grupper, bekreftet vårt materiale ingen tidligere positive funn.

Larere. I to enkeltstudier er det påvist økt forekomst av Down syndrom og urinveisobstruksjon hos barn av mannlige lærere $(11,13)$. Til tross for stor yrkesgruppe viste vårt materiale ingen økt risiko for de analyserte misdannelsene.

Elektriske yrker. Økt forekomst er rapportert for nevralrørsdefekter (15), spina bifida, leppeganespalte og 
syndactyli (13). Til tross for at den analyserte gruppen var stor, ble ingen økt risiko påvist.

Bonder. Økt forekomst er rapportert for nevralrørsdefekter (15), anencephalus (10), Down syndrom og reduksjonsdefekter $(17,18)$ og hypospadi hos barn av bønder og gartnere (13). Ingen økt risiko ble påvist i vårt materiale selv om den analyserte gruppen var stor.

Diverse andre yrker. Økt risiko for syndactyli er rapportert hos barn av arkitekter (13) og polydactyli hos barn med fedre i forsvaret (11). Tidligere funn av økt risiko for syndactyli hos arkitekter ble støttet $\mathrm{i}$ vårt materiale. Til tross for at den eksponerte gruppen er liten (1674), var risikoen signifikant forhøyet. På grunn av yrkeskoding på tre-siffer nivå inkluderes også bygningssjefer, generalplanleggere og reguleringssjefer. Ved bruk av utdannelseskoden for arkitekter for å bedre klassifiseringen, ble utvalget lite med kun to tilfeller. Økt forekomst av polydactyli hos barn av fedre i forsvaret ble ikke bekreftet.
For små yrkesgrupper vil det alltid være problemer med å avdekke økt risiko for misdannelser. Registerstudier hvor materialet fra flere nasjonale fødselsregistre blir kombinert, vil øke datamengden, men problemer med feilklassifisering vil trolig øke da fars yrkeseksposisjon vil være avhengig av land, type arbeidsplass, spesialisering i yrket, utdannelse og barnets fødselsår.

Dersom man får gjennomslag for registrering av foreldres yrker i meldingen til Medisinsk fødselsregister, og samordner dette med registrering i de andre nordiske land, fortrinnsvis med oppfølgningsopplysninger om misdannelser, vil man innen overskuelig fremtid kunne etablere en kohort som bedre ville kunne avdekke yrker med økt risiko for misdannelser. I en slik kohort vil det også være mulig å kombinere ulike yrker med felles yrkeseksposisjon, og analysere forekomst av spesifikke misdannelser hos avkommet.

\section{REFERANSER}

1. Olshan AF, Schnitzer PG. Paternal occupation and birth defects. Male mediated developmental toxicity. New York: Plenum Press, 1994.

2. Blatter BM, van der Star, Roeleveld N. Review of neural tube defects: Risk factors in parental occupations and the environment. Environ Health Perspect 1994; 102 (2): 140-5.

3. Daniell WE, Vaughan TL. Paternal employment in solvent related occupations and adverse pregnancy outcomes. Br J Ind Med 1988; 45: 193-97.

4. Hemminki K, et al. Congenital malformations by the parental occupation in Finland. Int Arch Occup Environ Health 1980; 46: 93-8.

5. Kristensen P, Irgens LM, Daltveit AK, Andersen A. Perinatal outcome among children of men exposed to lead and organic solvents in the printing industri. Am J Epidemiol 1993; 137 (2): 134-44.

6. Medisinsk fødselsregister: Årsmelding 1993.

7. Vollset SE, Hirji KF, Tang ML, Elashoff RM. Fast computation of exact confidence limits for the common odds ratio in a series of 2x2 tables. J Am Stat Assoc 1991; 86 (414): 406-9.

8. Irgens A, Krüger K, Skorve AH, Irgens LM. Yrke og reproduksjonsutfall, en populasjonsbasert registerstudie i Norge 1970-1993. 1996; ISBN 82-7788-036-7.

9. Fedrick J. Anencephalus in the Oxford linkage study area. Dev Med Child Neurol 1976; 18: 643-56.

10. Brender JD, Suarez L. Paternal occupation and anencephaly. Am J Epidemiol 1989; 131 (2): 517-20.

11. Olshan AF, Tschenke K, Baird PA. Paternal occupation and congenital anomalies in offspring. Am J Ind Med 1991; 20: 447-475.

12. Olsen J. Risk of exposure to teratogens amongst laboratory staff and painters. Dan Med Bull 1982; 30: 24-8.

13. McDowall ME. Occupational reproductive epidemiology. Series SMPS 50: London: Her Majesty's Stationary Office, 1985.

14. Ericson JD, Cochran WM, Andersen CE. Parental occupations and birth defects, a preliminary report. Contrib Epidemiol Biostat 1979; 1: 107-17.

15. Poldenak AP, Janerich DT. Uses of available record systems in epidemiologic studies of reproductive toxicology. Am J Ind Med 1983; 4 (1-2): 329-48.

16. OPCS Monitor. Congenital malformations and parents occupation. MB3 1982/1. London: Office of Population Censuses and Surveys, 19XX.

17. Olshan AF, Baird PA, Tschenke K. Paternal exposure and the risk of Down syndrome. Am J Hum Genet 1989; 44: 646-51.

18. Schwartz DA, Newsum LA, Markowitz, Heifetz R. Parental occupation and birth outcome in an agricultural community. Scand J Work Environ Health 1986; 12: 51-54. 